\title{
Equivalence and Research Design Optimization for International Market Segmentation
}

\author{
Larry L. Carter \\ High Point University
}

The massive growth of global competition has led firms to attempt various international market segmentation schemas; however, creating effective cross-border strategies is often fraught with unique challenges. The purpose of this study is to address the issues concerning equivalence and to propose a two-stage approach towards effective international market segmentation. The study consolidates equivalence issues specific to international research that may increase the likelihood of bias into the segmentation process. An exhaustive set of propositions is attempted to help firms improve their international market segmentation efforts and bolster their competitiveness in this global marketplace.

Keywords: Market Segmentation, Global Research, Equivalence, International Consumer Segments

\section{INTRODUCTION}

Market segmentation is commonly viewed by marketing managers as an essential tool for strategic planning, serving multiple roles in executive decision making on issues concerning competitive strategy, targeting, positioning, and product development (Lee, 1992). The increase in global competition over the past few decades has led to the development of international market segmentation as a key factor in marketing products to a worldwide audience (Ter Hofstede, Steenkamp, \& Wedel, 1999). Currently researchers are investigating international segmentation as a possible answer to the never-ending global marketing debate about standardization versus local adaptation, attempting to establish a means to create consumer segments that transcend geographical boundaries (Budeva \& Mullen, 2014).

From an historical perspective, the need to segment markets became apparent to both academics and practitioners through the emergence of marketing management during the 1950s. Wendell Smith, recognized as the pioneer of market segmentation, made the case for both product differentiation and market segmentation as alternative marketing strategies that are actually complementary to one another and effective in strengthening the product positioning for a company (Smith, 1956). Soon after Smith's article was published, the concept of market segmentation became a hotly contested topic among researchers, leading to the development of various market segmentation bases and methodologies. It has been commonly considered by many researchers as a direct consequence of the marketing concept and serves as one of the primary ways in which to operationalize the concept (e.g., Kale \& Sudharshan, 1987; Wind \& Douglas, 1972).

Claycamp and Massey (1968) extended the classical microeconomic theory of market segmentation into a multi-stage theory consisting of segmenting by perfect discrimination among customers, customer 
segmentation with institutional constraints, micro-segmentation, and macro-segmentation. During that same year, benefit segmentation was proposed by as an alternative, yet legitimate basis for effective consumer segmentation (Haley, 1968). While various bases for market segmentation have been identified and assessed, many researchers contend that the concept of segmentation depends on the firm's marketing objectives and cannot be viewed from a single uniform approach. For example, Assael and Roscoe (1976) state that two criteria must be evaluated, which in turn will alter the approach towards effective market segmentation. According to these researchers, segmentation is initially based on either consumer response to a set of marketing stimuli or to actual changes to the levels of said marketing stimuli. Secondly, the formation of segments must also be based on one or a group of behavioral criteria. Other researchers argue the need for grounded theory within the study of market segmentation and propose resource advantage theory as a viable theoretical basis (Hunt \& Arnett, 2004). These authors substantiate the importance of market segmentation by reiterating the three basic assumptions of all market segmentation strategies. First of all, it is assumed that markets are able to be divided into relatively homogeneous consumer segments. Secondly, a firm's product offerings can often be designed to meets the needs of these segments. And lastly, strategies that target these segments can lead to competitive advantages for the firm. Despite contentions among researchers as to how to appropriately create and implement market segmentation, it continues to be a thriving and relevant field of study with the marketing community.

International market segmentation, having a shorter life span than its domestic counterpart, first appeared as a field of study during the 1970s. At the onset, researchers contended that global strategies are dependent upon the firm's ability to successfully segment world markets (Sethi, 1971). This segmentation can be accomplished either by grouping countries into homogeneous clusters or by grouping homogeneous consumers across national boundaries. During the 1970s and 1980s, this mindset led to the majority of research studies focusing on segmentation strategies that were rooted in countrybased or geographical segmentation rather than consumer-oriented bases (Kale \& Sudharshan, 1987). During that time, international market segmentation also served as an appropriate tool for global standardization by means of identifying homogeneous global markets for which firms can standardize specific marketing mix variables toward. These arguments in favor of global standardization were based on three assumptions (Levitt, 1983). As time goes by, consumers' needs and interests are becoming more homogeneous across the globe. Consumers are also willing to sacrifice their preferences towards product features, functions, and design, opting for high quality at lower prices. The third assumption is that focusing on global markets may help firms achieve substantial economies of scale in both marketing and production.

Much debate has transpired over the years within the marketing research community regarding the feasibility of global standardization. Some researchers suggested that three main conditions will most likely facilitate the successful implementation of global standardization strategies, specifically the presence of global market segments, potential economies of scale from standardization practices, and the presence of a global distribution infrastructure (Segal-Horn \& Davison, 1992). In opposition to the concept of global standardization, others contend that cross-national or within-country segmentation is more feasible than country-specific segmentation. (Yavas, Verhage, \& Green, 1992). In addition, Barker (1993) argued that global standardization is product-oriented rather than consumer-oriented, thus ignoring the real differences among consumer segments. Therefore, standardization is not a viable option for most firms due to local and cultural barriers, including languages, societal customs and norms, technological transfers, and governmental controls. In further support of local adaptation over global standardization, researchers have investigated the need for firms to adapt their marketing strategies for each targeted country, thus adopting a more localized approach (Davidson \& Harrigan, 1977).

In contrast, Cheron and Kleinschmidt (1985) contend that the main purpose of market segmentation is to identify and delineate homogeneous markets for standardization of specific elements of a firm's marketing strategy. Using the classic price discrimination model as a theoretical basis, firms utilizing a market segmentation strategy will more likely increase their expected probability (Wind, 1978). Other researchers have also examined the possible existence of marketing universals to provide a strong basis for global marketing strategies (Dawar \& Parker, 1994). These marketing universals are defined as 
consumer behaviors within a segment and toward a particular product category that are invariant across cultures.

In order to determine the feasibility of global standardization for specific marketing mix variables, an accurate assessment of cross-national segments must be conducted (Craig \& Douglas, 2000). The segmentation process initially begins with defining the objectives of market segmentation with respect to the firm's needs. Once these objectives are established, an effective and efficient research design is then developed to meet those objectives. Unlike domestic country research, international research is plagued with unique complexities such as data availability, cultural equivalency issues, and higher costs that are typically associated with collecting data in foreign countries. Due to its complexity and difficulty in implementation, international market segmentation has unfortunately been under-researched; however, the need for cross-border research will continue to increase as international business activities flourish in our active global marketplace (Papadopoulos \& Martin, 2011). The purpose of this study is three-fold. The first objective is to investigate and identify research design issues within the field of international market segmentation. Secondly, a framework is proposed to optimize the research design in order to provide more effective cross-national market segment schemas. Finally, suggestions for future research are provided to guide potential directions to expand the field of international market segmentation.

\section{CONCEPTUAL FRAMEWORK AND PROPOSITIONS}

Searches of key terminology relating to international market segmentation were initially conducted using research databases such as ABI Inform. After identifying relevant articles, additional literature was identified and selected from the reference sections of these articles. Only those studies that directly addressed market segmentation within an international context were selected for further analysis. In total, 73 studies met this criterion and were included in the literature review. An overwhelming 49 studies were empirical works addressing consumer markets, while seven studies involved industrial markets and 17 articles were conceptual in nature. While the earliest article was published in 1966, nearly three quarters of the 73 studies were published after 1989, paralleling the increase of globalization and reflecting the relevance of market segmentation within an international context.

As an extension of the conventional research process itself, international marketing research also consists of six sequential steps; problem recognition, research approach development, research design, fieldwork, data analysis, and reporting (Malhotra, Agarwal, \& Peterson, 1996). This study evaluates potential issues that commonly arise within the research design component of the aforementioned process. Analyzing the international segmentation studies has revealed several areas of discrepancy, particularly the choice of segmentation bases, data sources, analytical methods, and various equivalence issues.

Figure 1 represents the main components influencing the effectiveness of the research design for these types of studies. A two-stage approach is proposed as the optimal market segmentation process, consisting of initial country pre-screening and subsequent consumer groupings within selected country clusters. When conducting cross-national research, several equivalence issues may arise during the research design process. Construct equivalence must be established across the countries of interest by analyzing its functional conceptual category as well as its measurement components. Measurement equivalence involves several considerations as well, particularly in areas of translation, calibration, metrics, and scoring. Finally, sampling equivalence must be assessed to ensure that the sample sizes from each country of interest are proportional to the size of the populations from which they represent. The following sections of this study discuss each component in greater detail and suggest propositions that contribute to the optimization of the research process. 


\section{FIGURE 1 \\ A RESEARCH DESIGN FRAMEWORK FOR MAXIMIZING INTERNATIONAL SEGMENTATION EFFECTIVENESS}

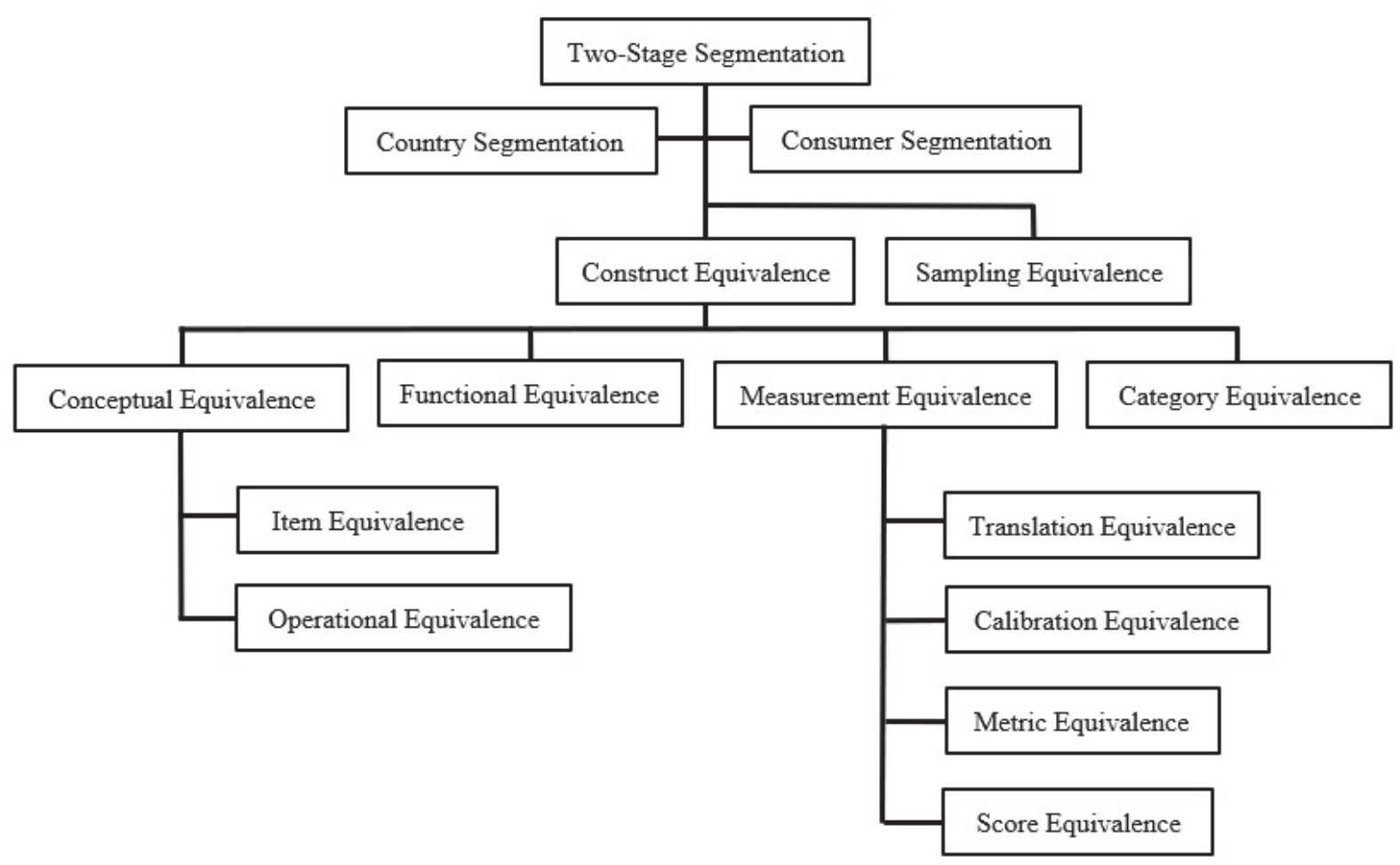

Segmentation bases are sets of variables and/or characteristics used to categorize potential customers into groups consisting of homogeneous members, while being heterogeneous to other groups. A typical approach to categorizing segmentation bases tends to center on the segregation of these bases into three categories, specifically macro-level criteria, micro-level criteria, and criteria consisting of a combination of both macro-level and micro-level variables.

\section{Macro-level Criteria}

Studies commonly use country or regional level information that is specific to a geographic area and are oftentimes based on aggregated data regarding the consumers or businesses within that country or region. International market segmentation is commonly performed by clustering markets based on discrete environmental factors, such as GNP per capita, political system and/or its stability, geographic region and/or its proximity, and energy consumption (Luqmani, Yavas, \& Quraeshi, 1994). Information concerning this type of criteria generally consists of aggregated data from secondary research sources that are readily available.

Multiple criteria are typically used to classify countries, most of which containing some measure of economic growth and development (Schlegelmilch, 2016; Walters, 1997). For example, one study identified four macro-level factors (GNP per capita, literacy rate, number of scientists and engineers, and the proportion of manufacturing and service sectors to the total GNP) that determines a country's level of national innovativeness (Lee, 1990). Others have examined consumption patterns based on the ICP (i.e., International Comparison Programme) and GNP per capita (Oyewole, 1998) as well as aggregated consumer data, including product usage rates (Nakip, 1999) and total sales per country (Kumar, Ganesh, \& Echambadi, 1998) for the purposes of country segmentation. 
Culture-related variables have also generated a great deal of interest as viable bases for market segmentation. Vandermerwe and L'Huillier (1989) utilized regional level variables pertaining to culture, geography, demographics, and economics to assess the feasibility of segmenting European countries. On a grander scale, Nachum (1994) investigated 37 cultural and economic country characteristics of import demand within 78 less-developed countries. The author contends that the strongest demand influencers are trade, industrialization, finance, and technology for industrial type goods, while consumer goods demand is determined mostly by income and the stability of the country's currency. More importantly, the study provided strong support for the insignificance of GDP and GNP distribution as appropriate bases for market segmentation.

It is fairly safe to say that most commonly known and heavily referenced national cultural variables are Hofstede's (1980) four dimensions of national culture. After rigorous development, Hofstede used these dimensions to identify seven distinct country clusters based on each country's levels of masculinity/femininity, individualism/collectivism, power distance, and uncertainty avoidance. Subsequently, several studies have utilized these four national cultural dimensions to segment country markets. For example, Kale (1995) attempted to use Hofstede's schema to segment 17 Western European countries. Although three country clusters emerged from this analysis, only one segment matched Hofstede's original country classifications. It is interesting to note that the results from this particular study varied greatly from those found in comparable research. For example, Steenkamp (2001) combined both Schwartz's (1994) seven and Hofstede's four dimensions to segment 24 countries across a more comprehensive array of national cultural dimensions. Four national cultural dimensions emerged as the most dominant bases for country segmentation, specifically autonomy vs. collectivism, egalitarianism vs. hierarchy, mastery vs. nurturance, and uncertainty avoidance

\section{Micro-level Criteria}

Contrary to macro-level bases, micro-level segmentation criteria are typically developed using disaggregated information about individual consumers. Demographic variables are commonly utilized as consumer segmentation factors and generally include age, sex, income level, social class, and educational level (Walters, 1997). For instance, Hammond, Ehrenberg, and Goodhardt (1996) compiled eight demographic and socio-economic measures of households for competitive brands. With regards to the proliferation of online shopping and e-commerce, Shiu and Dawson (2002) investigated key demographic variables that were useful for effectively segmenting Internet shoppers. Attitudes of individuals have also been examined in conjunction with demographic variables to determine appropriate segmentation strategies (Chiesl \& Lamb, 1983); while other researchers have relied solely on consumer attitudes for segmentation purposes (Verhage, Dahringer, \& Cunduff, 1989).

Similar in use to demographics, psychographic variables are another important set of segmentation criteria that consist of lifestyle factors involving the activities, interests, and opinions of the individual (e.g., Boote, 1983; Domzal \& Unger, 1987; Walters, 1997). With regards to recent studies, psychographic variables such as cosmopolitanism (Terasaki, 2016) and green (i.e., environmentally conscious) lifestyles (Yilmazsoy \& Schmidbauer, 2015) have gained support as feasible bases for cross-national segmentation wile reflecting emerging consumer trends.

Behavioral variables are those factors that best describe an individual's actions and intentions as a response to marketing stimuli. Certain patterns of behavior are found to be homogeneous within particular groups of consumers and serve as appropriate bases to delineate market segments. For example, Yavas, Verhage, and Green (1992) examined two individual-level behavioral measures (brand loyalty and perceived risk) across a set of national markets from various continents. Their findings support the notion that cross-national segmentation is more feasible than either country-specific segmentation or even global standardization. Benefit segmentation proactively defines the benefits sought by consumers to fulfill specific needs and have been extensively researched as a potential basis for segmentation (e.g., Crawford, Garland, \& Ganesh, 1988; Domzal \& Unger, 1987; Wu, 2001; Young, Ott, \& Feigin, 1978). Values have also been identified as a significant determinant of behavior and consequently received substantial fanfare by researchers studying the feasibility of value segmentation (e.g., Daghfous, Petrof, \& Pons, 1999; 
Gordon, 1976; Huber, Herrmann, \& Morgan, 2001; Kamakura et al., 1993; Madi, 2016; Muller, 1991; Wedel, Ter Hofstede, \& Steenkamp, 1998).

Like attitudes, consumer values have also been examined in conjunction with demographic variables to determine their utility for segmentation (Lascu, Manrai, \& Manrai, 1996). Finally, some studies have employed complex sets of micro-level variables to group market segments. As an example, Cui and Lui

(2001) used a combination of demographics, consumer attitude, psychographics, media usage, household expenditure, consumption patterns, and domestic vs. foreign brand recall measures to investigate Chinese consumer segments. They contend that multinational corporations incorrectly assume that emerging middle class segments in transitional economies are similar to that of Western countries, positing that these emerging segments must be calculated from local conditions.

\section{Criteria Combinations}

Researchers have also argued that a combination of macro-level and micro-level criteria may serve as the most comprehensive and feasible bases for cross-national segmentation (e.g., Bijmolt, Paas, \& Vermunt, 2004; Jain, 1989; Kreutzer, 1988; Schuster \& Bodkin, 1987). According to Luqmani, Yavas, and Quraeshi (1994), the use of macro-level segmentation bases is actually influenced greatly by microlevel characteristics, thus both types of segmentation bases highly complement one another. Once specific macro-level variables have been identified, micro-level criteria that influence consumer product preferences should then be evaluated for a more comprehensive understanding of segmentation. This combination criteria approach is exemplified in a study that initially used GDP per capita to screen country candidates for potential segmentation. As a follow up, the author evaluated consumer responses to marketing stimuli as the final basis for the segmentation schema (Souiden, 2002).

Several other relatively recent studies have also implemented the criteria combination approach, each using a different assembly of macro-level and micro-level segmentation variables. Agarwal (2003) utilized a combination of individual demographic variables with country-level variables, specifically consumption, mobility, trade, country size, consumer price index, and communication infrastructure. In contrast, Bijmolt, Paas, and Vermunt (2004) relied on a combination of four demographic characteristics for consumer segmentation in conjunction with the relative size of consumer segments for country segmentation.

Table 1 provides a sample of studies selected from the literature review and classifies their corresponding segmentation bases according to this macro/micro/combination schema. These studies represent the earliest uses of their respective variables for segmentation purposes and are listed in chronological order. 
TABLE 1

\section{TYPOLOGY OF MARKET SEGMENTATION BASES}

\begin{tabular}{|rl|}
\hline Macro-Level (Country/Region) Variables \\
\hline 1. & National economic development (Day, Fox, \& Huszagh, 1988) \\
2. Culture, geography, demographics, and economics (Vandermerwe \& L'Huillier, 1989) \\
3. Sociodemographic country characteristics (Helsen, Jedidi, \& DeSarbo, 1993) \\
4. Cultural and economic country characteristics of import demand (Nachum, 1994) \\
5. Market potential variables of countries (Kumar, Stam, \& Joachimsthaler, 1994) \\
6. Hofstede's four national culture dimensions (Kale, 1995) \\
7. Aggregate national sales (Kumar, Ganesh, \& Echambadi, 1998) \\
8. ICP-based consumption patterns and GNP per capita (Oyewole, 1998) \\
\hline Micro-Level (Consumer/Individual) Variables \\
\hline 1. Personal and interpersonal values of students (Gordon, 1975) \\
2. Benefits sought by consumers (Young, Ott, \& Feigin, 1978) \\
3. Psychographics (Boote, 1983) \\
4. Consumer attitudes (Verhage, Dahringer, \& Cundiff, 1989) \\
5. Behavioral measures of consumers (Yavas, Verhage, \& Green, 1992) \\
6. Sensory perceptions of consumers (Moskowitz \& Robino, 1994) \\
7. Demographics, attitudes, psychographics, lifestyles, media usage, household expenditure, consumption \\
8. Prodterns, and brand recall measures (Cui \& Lui, 2001) \\
Combination of Macro-Level and Micro-Level Variables \\
\hline 1. Both macro-level and micro-level segmentation variables, such as geography, attitudes, firm size, end \\
market, usage rates, and importance (Schuster \& Bodkin, 1987) \\
2. GDP per capita to initially screen country candidates; them segmented by consumer responses to \\
3. Inarketing stimuli (Souiden, 2002) \\
4. Donsumer price index, and communication infrastructure (Agarwal, 2003) \\
2egmographic characteristics for consumer segmentation; relative size of consumer segments for country \\
\hline
\end{tabular}

\section{Criteria Classifications}

Market segmentation bases can also be delineated across other dimensions besides the aforementioned macro-level and micro-level analyses. These dimensions are typically either general or product-specific in nature and are either observable or unobservable (Wedel \& Kamakura, 1998). Contrary to product-specific or domain-specific bases, a general segmentation basis is comprised of criteria that are independent of products, services, or situations. In addition, an observable basis can be measured directly while an unobservable basis is inferred.

According to the early works of Frank, Massy, and Wind (1992), segmentation bases within both consumer and industrial markets can be delineated using both of these categorizations (observable/unobservable and general/product-specific). Observable general bases for market segmentation comprise of cultural variables, geographic variables, neighborhood classifications, geographic mobility, demographic and socio-demographic variables, postal code classifications, household life cycle, household and firm size, standard industrial classifications, and media usage (Wedel \& Kamakura, 1998). Unobservable general bases generally fall within one of three classifications; personality traits, personal values, and lifestyles. Observable product-specific bases are generally comprised of criteria related to buying and consumption behavior, such as user status, usage frequency, brand loyalty, store loyalty, store patronage, stage of adoption, and usage situation. In contrast, unobservable product-specific bases involve product-specific psychographics, product benefit perceptions and importance, brand attitudes, brand preferences, and behavioral intentions. 


\section{Two-stage Segmentation}

Several evaluative criteria schemas have been developed to assess the effectiveness of market segmentation bases; however, these schemas all contain similar dimensions that measure the distinctiveness of market segments, their accessibility by a firm's marketing efforts, and their substance relative to segment size. According to Wedel \& Kamakura (1998), six dimensions (identifiability, substantiality, accessibility, responsiveness, stability, and actionability) have been identified to aid in determining the effectiveness and profitability of market segmentation bases. Identifiability is the extent to which groups of consumers can be categorized into distinct segments. Substantiality pertains to the size of the segment in terms of providing enough opportunity for profit generation. Accessibility is the degree in which the segments are reachable through promotional and distribution efforts. Responsiveness refers to the ability of the segment to respond uniquely to the marketing efforts that are targeted at them. Stability occurs when segments are stable enough over time to provide the underlying basis for marketing strategy development. And finally, actionability refers to the ability of segments to provide guidance for marketing mix decisions.

While all six of these dimensions are important to the marketing manager in evaluating segmentation bases, trade-offs generally exist between the dimensions, based on the nature of the basis criteria. For the most part, general bases tend to high in identifiability, accessibility, and stability while ranking low in actionability and responsiveness. In stark contrast, product-specific bases are typically low in identifability, accessibility, and stability while ranking high in responsiveness and actionability. Regardless, the substantiality dimension must be high in all cases, serving as a prerequisite for effective market segmentation (Wedel \& Kamakura, 1998).

This trade-off may be avoided by considering a two-sage segmentation solution, such as the one provided by Kamakura et al. (1993) or more recently by Gaston-Breton and Martin (2011). Two considerations must be taken into account when selecting the appropriate variables for each stage: 1) the current state of the marketing and consumer behavior knowledge about the relevance of basis criteria and descriptors of market segments and 2) the actual needs of the firm itself (Wind, 1978). Therefore, the selection of segmentation criteria is uniquely dependent upon the objectives of the segmentation process and will vary across studies.

During the first stage, countries should be grouped on a general basis into country clusters with similar socio-economic and cultural characteristics to generate high identifiability, accessibility, and stability. According to Steenkamp and Ter Hofstede (2002), identifying country clusters serves a number of purposes. At face value, the segmentation and clustering of countries serves as a screening process to filter out those countries that have a lack of fit with the firm's objectives or are deemed as unattractive to the firm due to unacceptable country-level characteristics. The first segmentation stage also reveals additional information about the country to the firm that may be useful when developing marketing strategies. In addition, the relative homogeneity of these country clusters should increase the equivalence of domain-specific constructs and provide greater segment stability within the clusters.

In the second stage, the consumers within these targeted country clusters should be segmented according to product-specific or domain-specific bases to increase the responsiveness and actionability of the segmentation process. Disaggregated data is analyzed for the identification of cross-national market segments within each country cluster that was identified during the first segmentation stage. Given the benefits of this two-step process over country segmentation or cross-national consumer segmentation, the two-stage segmentation approach is recommended for optimized market segmentation in an attempt to bolster profit maximization. This view is clearly expressed within the first two propositions presented in this study.

P1: The use of the two-stage market segmentation process will lead to greater firm profitability when compared to using country segmentation to develop targeted market segments.

P2: The use of the two-stage market segmentation process will lead to greater firm profitability when compared to using cross-national segmentation to develop targeted market segments.

Journal of Marketing Development and Competitiveness Vol. 13(3) 2019 


\section{Equivalence Issues}

A paramount concern in cross-cultural research design is the establishment of various equivalences with regards to the scales and measures across all cultural contexts within the study (Garber, Boya, \& Hyatt, 2018). In terms of international market segmentation, equivalence issues can be broadly segregated into construct equivalences and sampling equivalences. Construct equivalence addresses the problem of whether the constructs have the same meaning and significance within the different cultures and can be subdivided into four categories, specifically conceptual equivalence, functional equivalence, category equivalence, and measurement equivalence. Possible sources of construct equivalence discrepancies include between-country differences for occupational classifications, population density specifications, definitions of retailing, and product class definitions (Steenkamp \& Ter Hofstede, 2002). Despite its importance in international research, construct equivalence is oftentimes overlooked with most studies failing to report sufficient controls or measures taken by researchers to address this issue.

Conceptual equivalence deals with the issue of whether the meanings of the constructs, research stimuli, and research materials are equal across countries and is typically comprised of additional equivalences, namely operational equivalence and item equivalence (Bhalla \& Lin, 1987). In transitioning from theory to measurement, operational equivalence is concerned with whether the operationalization of the concepts of interest is similar enough across the cultures of interest. Following the same line of reasoning, item equivalence requires that scale items to be measured by the same instrument (Hui \& Triandis, 1985). The next two propositions state the importance of conceptual equivalence for international segmentation research.

P3: Segmentation research designs that control for the operational equivalence of constructs across countries will produce better market segments than those that do not control for it.

P4: Segmentation research designs that control for the item equivalence of constructs across countries will produce better market segments than those that do not control for it.

Aside from conceptual equivalence, Malhotra, Agarwal, and Peterson (1996) identified additional construct equivalency components. Functional equivalence is concerned with the degree in which the phenomenon is related to the same functional problem among the countries of interest. It is attained when the behavior has been established as a response to a problem that is shared by members of these national cultures. Category equivalence deals with the issue of whether the grouping of objects, research stimuli, and behaviors are equal across countries.

P5: Segmentation research designs that control for the functional equivalence of constructs across countries will produce better market segments than those that do not control for it.

P6: Segmentation research designs that control for the category equivalence of constructs across countries will produce better market segments than those that do not control for it.

Measurement equivalence refers to the degree in which each scale item measures the construct in the same manner across countries and is comprised of four types of equivalences. Potential between-country differences in measurement may exist for response styles, scale interpretations, measurement interpretations, and score interpretations (Steenkamp \& Ter Hofstede, 2002). Calibration equivalence deals with whether the units of measurement are the same across cultures, while translation equivalence addresses the issue of whether the translated version of the questionnaire actually preserves the same meaning and ideas of the original version (Dimanche, 1994). A common solution to avoiding translation non-equivalency among questionnaire versions is to simply employ the back translation method (Breslin, 1980). 
P7: Segmentation research designs that control for the calibration equivalence of constructs across countries will produce better market segments than those that do not control for it.

P8: Segmentation research designs that control for the translation equivalence of constructs across countries will produce better market segments than those that do not control for it.

Another component of measurement equivalence focuses on score equivalence, which is defined as the equivalence of the scoring of the measures across countries. This can be straightforwardly tested using confirmatory factor analysis for repeated measures of constructs (Steenkamp \& Baumgartner, 1998). A common culprit of non-equivalent scores is due to differences in response styles across national cultures. There are several methods used to detect these differences, including structural equations modeling (Steenkamp \& Baumgartner, 1998), optimal scaling (Mullen, 1995), regression analysis (Hui \& Triandis, 1985), and comparing means and standard deviations (Greenleaf, 1992). Standardizing, ipsatizing, or normalizing the data typically alleviates the problem after its detection. The fourth and final component that is associated with measurement equivalence is metric equivalence. It refers to the equality of the coherence and structure of the psychometric properties of the data exhibited across cultures (Bhalla \& Lin, 1987; Mullen, Milne, \& Didow, 1996). In other words, scale intervals and scale origins must have the same meaning across cultures to produce meaningful findings resulting from cross-cultural comparisons.

P9: Segmentation research designs that control for the score equivalence of constructs across countries will produce better market segments than those that do not control for it.

P10: Segmentation research designs that control for the metric equivalence of constructs across countries will produce better market segments than those that do not control for it.

Sampling equivalence is another important issue that is often overlooked by researchers tasked with collecting data within a foreign environment. This type of equivalence is attained when all of the country samples exhibit the same characteristics and are representative of the population of interest (Sin, Cheung, \& Lee, 1999). Furthermore, the sampling frames from which individuals are selected as respondents should be equivalent across the countries that are being compared. Researchers oftentimes employ convenience sampling, making it very difficult to assess the level of representativeness of the sample. If possible, researchers should consider matched sampling as a more reliable method of sampling for crossnational research studies. Matched sampling is implemented to overcome the lack of randomization in multicultural samples selection and is also useful for controlling extraneous effects due to variances in respondents' age, occupation, and other demographic variables (e.g., Kohlman et al., 2003; LeBlanc \& Herndon, 2001; Moore, Kennedy, \& Fairhurst, 2003; Spreng \& Chiou, 2002). Two possible solutions exist to ensure sampling equivalence. The researchers can either draw sample sizes that are proportionate to the population size or assign weights to the samples that are disproportionate to their respective population size.

P11: Segmentation research designs that control for the sampling equivalence of constructs across countries will produce better market segments than those that do not control for it.

\section{CONCLUSIONS}

In summary, this study provides directions to optimize or, at the very least, improve the research design for empirical studies involving international segmentation. The first suggestion is to incorporate some sort of two-stage segmentation process that incorporates both macro-level and micro-level criteria to serve as segmentation bases. This practice will provide a more holistic assessment of potential segmentation variables that most likely are inter-related to some degree, resulting in stronger support for 
the segmentation process that is used in the study. The second objective of this study is to consolidate the various equivalency issues that have been identified in previous cross-cultural research. If addressed properly, these equivalencies will actually provide stronger support for the study's findings by alleviating several biases that may be introduced at various stages of the research process. Potential solutions for the various equivalence issues are also provided within this study.

There are several suggestions to help guide the direction for future research in this area. Limited research has been conducted outside of the domain of international segmentation of consumer markets; therefore, there is ample space for future studies to explore other sectors such as retailing, servicesoriented marketing, database marketing, online shopping, and industrial marketing within an international context. Aside from expanding into other sectors, researchers could also venture into areas of managerial decision-making, strategy implementation, and competitive strategy formation by utilizing international market segmentation. Most studies that developed international market schemas failed to discuss how to implement the schemas successfully. Research has also been somewhat limited with regards to regional coverage and international segmentation, focusing mainly on industrialized regions; therefore, in depth examination of potential market segments in less industrialized nations or emerging economies is encouraged. As for methodological concerns, researchers should continue to develop or adopt the latest statistical methods (e.g., latent curve modeling, time series modeling, mixture models, and latent Markov models) and validate their results by comparing similar findings that were generated by other methods of analysis (Agarwal, 2003; Askegaard \& Madsen, 1998; Huzgagh, Fox, \& Day, 1986).

Certain limitations exist with regards to this study proposal and should be acknowledged. Although the study provides an extensive overview of the research conducted in the area of international segmentation, its article selection process was not collectively exhaustive due to limited resources in gaining full access to all relevant journals. Future research should attempt to include a more comprehensive review of articles on the subject matter with the inclusion of those published within disciplines outside of marketing. Secondly, while some solutions were provided in the study to aid researchers in addressing equivalency issues, the lack of details within these solutions pose as another potential limitation of the study. Thirdly, to provide a more comprehensive and realistic analysis, researchers should consider other variables, such as the competitive environment and market dynamics with countries, as potential determinants for effective market segmentation.

Combined with the use of a two-stage (macro/micro) segmentation process and controls to increase equivalence across most areas of the research process, researchers will be able to more accurately create, assess, and compare legitimate market segments. From a managerial perspective, firms will be able to focus their resources toward the most viable segments in order to develop effective marketing strategies and maximize their profitability through efficiency and economies of scale. 


\section{REFERENCES}

Agarwal, M. K. (2003). Developing global segments and forecasting market shares: A simultaneous approach using survey data. Journal of International Marketing, 11(4), 56-80.

Askegaard, S., \& Madsen, T. K. (1998). The local and the global: Exploring traits of homogeneity and heterogeneity in European food cultures. International Business Review, 7(6), 549-568.

Assael, H., \& Roscoe Jr., A. M. (1976). Approaches to market segmentation analysis. Journal of Marketing, 40(4), 67-76.

Aurifeille, J-M., Quester, P. G., Lockshin, L., \& Spawton, T. (2002). Global vs. international involvement-based segmentation: A cross-national exploratory study. International Marketing Review, 19(4), 369-386.

Barker, A. T. (1993). A marketing oriented perspective of standardized global marketing. Journal of Global Marketing, 7(2), 123-130.

Bhalla, G., \& Lin, L. (1987). Cross-cultural marketing research: A discussion of equivalence issues and measurement strategies. Psychology \& Marketing, 4(4), 275-285.

Bijmolt, T. H. A., Paas, L. J., \& Vermunt, J. K. (2004). Country and consumer segmentation: Multi-level latent class analysis of financial product ownership. International Journal of Research in Marketing, 21(4), 323-340.

Boote, A. S. (1983). Psychographic segmentation in Europe. Journal of Advertising Research, 22,19-25.

Breslin, R. W. (1980). Translation and content analysis for oral and written material. In Triandis, H. C. \& Berry, J. W. (Eds.), Handbook of cross-cultural psychology. Boston, MA: Allyn \& Bacon, 297318.

Budeva, D. G., \& Mullen, M. R. (2014). International market segmentation: Economics, national culture and time. European Journal of Marketing, 48(7/8), 1209-1238.

Cheron, E. J., \& Kleinschmidt, E. J. (1985). A review of industrial market segmentation research and a proposal for an integrated segmentation framework. International Journal of Research in Marketing, 2(2), 101-115.

Chiesl, N., \& Lamb, S. W. (1983); Segmenting international industrial markets. Journal of the Academy of Marketing Science, 11(3), 250-258.

Claycamp, H. J., \& Massey, W. F. (1968). A theory of market segmentation. Journal of Marketing Research, 5(4), 388-394.

Craig, C. S., \& Douglas, S. P. (2000). International marketing research, $2^{\text {nd }}$ edition. Chichester, UK: John Wiley \& Sons.

Crawford, J. C., Garland, B. C., \& Ganesh, G. (1988). Identifying the global pro-trade consumer. International Marketing Review, 5(4), 25-33.

Cui, G., \& Lui, Q. (2001). Executive insights: Emerging market segments in a transitional economy: A study of urban consumers in China. Journal of International Marketing, 9(1), 84-106.

Daghfous, N., Petrof, J. V., \& Pons, F. (1999). Values and adoption of innovations: A cross-cultural study. Journal of Consumer Marketing, 16(4), 314-331.

Davidson, W. H., \& Harrigan, R. (1977). Key decisions in international marketing: Introducing new products abroad. Columbia Journal of World Business, 13, 15-26.

Dawar, N., \& Parker, P. (1994). Marketing universals: Consumers' use of brand name, price, physical appearance, and retailer reputation as signals of product quality. Journal of Marketing, 58(2), 8195.

Day, E., Fox, R. J., \& Huszagh, S. M. (1988). Segmenting the global market for industrial goods: Issues and implications. International Marketing Review, 5(3), 14-27.

Dimanche, F. (1994). Cross-cultural tourism marketing research: An assessment and recommendations for future studies. Journal of International Consumer Marketing, 6(3/4), 123-134.

Domzal, T., \& Unger, L. (1987). Emerging positioning strategies in global marketing. The Journal of Consumer Marketing, 4(4), 23-40.

Frank, R. E., Massy, W., \& Wind, Y. (1972). Market segmentation. Englewood Cliffs, NJ: Prentice Hall. 
Garber, L. L., Boya, U. O., \& Hyatt, E. M. (2018). Hypotheses of equivalence and their testing. Journal of Marketing Theory \& Practice, 26(3), 280-288.

Gaston-Breton, C., \& Martin, O. M. (2011). International market selection and segmentation: A two-stage model. International Market Review, 28(3), 267-290.

Gordon, L. V. (1975). The measurement of interpersonal values. Chicago, IL: Science Research Associates.

Gordon, L. V. (1976). Survey of interpersonal values - Revised manual. Chicago, IL: Science Research Associates.

Greenleaf, E. A. (1992). Improving rating scale measures by detecting and correcting bias components in some response styles. Journal of Marketing Research, 29(2), 176-188.

Haley, R. I. (1968). Benefit segmentation: A decision-oriented decision toll. Journal of Marketing, 32(3), 30-35.

Hammond, K., Ehrenberg, A. S. C., \& Goodhardt, G. J. (1996). Market segmentation for competitive brands. European Journal of Marketing, 30(12), 39-49.

Helsen, K., Jedidi, K., \& DeSarbo, W. S. (1993). A new approach to country segmentation utilizing multinational diffusion patterns. Journal of Marketing, 57(4), 60-71.

Hofstede, G. (1976). Culture's consequences: International differences in work related values. Beverly Hills, CA: Sage.

Huber, F., Herrmann, A., \& Morgan, R. E. (2001). Gaining competitive advantage through customer value oriented management. The Journal of Consumer Marketing, 18(1), 41-53.

Hui, C. H., \& Triandis, H. C. (1985). Measurement in cross-cultural psychology: A review and comparison of strategies. Journal of Cross-Cultural Psychology, 16(2), 131-152.

Hunt, S. D., \& Arnett, D. B. (2004). Market segmentation strategy, competitive advantage, and public policy: Grounding segmentation strategy in resource advantage theory. Australasian Marketing Journal, 12(1), 7-25.

Huszagh, S. M., Fox, R. J., \& Day, E. (1986). Global marketing: An empirical investigation. Columbia Journal of World Business, 20(4), 31-43.

Jain, S. C. (1989). Standardization of international marketing strategy: Some research hypotheses. Journal of Marketing, 53(1), 70-79.

Kale, S. H. (1995). Grouping Euroconsumers: A culture-based clustering approach. Journal of International Marketing, 3(3), 35-48.

Kale, S. H., \& Sudharshan, D. (1987). A strategic approach to international segmentation. International Marketing Review, 4(2), 60-70.

Kamakura, W. A., Novak, T. P., Steenkamp, J-B. E. M., \& Verhallen, T. M. M. (1993). Identification de segments de valeurs Pan-Europeens par un modele logit sure les rangs avec regroupements successifs (Identifying Pan-European value segments with a clusterwise rank-logit model). Recherche et Applications en Marketing, 8(4), 30-55.

Kolman, L., Noorderhaven, N. G., Hofstede, G., \& Dienes, E. (2003). Cross-cultural differences in Central Europe. Journal of Managerial Psychology, 18(1/2), 76-89.

Kreutzer, R. T. (1988). Marketing mix standardization: An integrated approach in global marketing. European Journal of Marketing, 22(10), 19-30.

Kumar, V., Ganesh, J., \& Echambadi, R. (1998). Cross-national diffusion research: What do we know and how certain are we? Journal of Production Innovation Management, 15(3), 255-268.

Kumar, V., Stam, A., \& Joachimsthaler, E. A. (1994). An interactive multicriteria approach to identifying potential foreign markets. Journal of International Marketing, 2(1), 29-52.

Lascu, D-N., Manrai, L. A., \& Manrai, A. K. (1996). Value differences between Polish and Romanian consumers: A caution against using a regiocentric marketing orientation in Eastern Europe. Journal of International Consumer Marketing, 8(3/4), 145-167.

LeBlanc, R. P., \& Herndon, N. C. (2001). Cross-cultural consumer decisions: consideration sets - a marketing universal? Marketing Intelligence \& Planning, 19(6/7), 500-507. 
Lee, C. (1990). Determinants of national innovativeness and international market segmentation. International Marketing Review, 7(5), 39-49.

Lee, R. S. (1992). Marketing dynamics analysis and multiple segmentation. Psychology \& Marketing, 9(1), 59-76.

Levitt, T. (1983). The globalization of markets. Harvard Business Review, 61(3), 92-102.

Luqmani, M., Yavas, U., \& Quraeshi, Z. A. (1994). A convenience-oriented approach to country segmentation. Journal of Consumer Marketing, 11(4), 29-40.

Madi, A. (2016). Using values to segment virtual consumers on social networking sites. Marketing Intelligence \& Planning, 34(5), 623-645.

Malhotra, N. K., Agarwal, J., \& Peterson, M. (1996). Methodological issues in cross-cultural marketing research: A state-of-the-art review. International Marketing Review, 13(5), 7-43.

Moore, M., Kennedy, K. M., \& Fairhurst, A. (2003). Cross-cultural equivalence of price perceptions between U.S. and Polish consumers. International Journal of Retail \& Distribution Management, 31(4/5), 268-280.

Moskowitz, H. R., \& Rabino, S. (1994). Sensory segmentation: An organizing principle for international product concept generation. Journal of Global Marketing, 8(1), 73-93.

Mullen, M. R. (1995). Diagnosing measurement equivalence in cross-national research. Journal of International Business Studies, 26(3), 573-596.

Mullen, M. R., Milne, G. R., \& Didow, N. M. (1996). Determining cross-cultural metric equivalence in survey research: A new statistical test. Advances in International Marketing, 8(2), 145-157.

Muller, T. E. (1991). Using personal values to define segments in an international tourism market. International Marketing Review, 8(1), 57-70.

Nachum, L. (1994). The choice variables for segmentation of the international market. International Marketing Review, 11(3), 54-67.

Nakip, M. (1999). Segmenting the global market by usage rate of industrial products. Industrial Marketing Management, 28(2), 177-195.

Oyewole, P. (1998). Country segmentation of the international market using ICP-based consumption patterns. Journal of Global Marketing, 11(4), 75-94.

Papadopoulos, N., \& Martin, O. M. (2011). International market selection and segmentation: Perspectives and challenges. International Marketing Review, 28(2), 132-149.

Schlegelmilch, B. B. (2016). Segmenting, targeting and positioning in global markets. In: Global marketing strategy: Management for professionals. New York, NY: Springer.

Schuster, C. P., \& Bodkin, C. D. (1987). Market segmentation practices of exporting countries. Industrial Marketing Management, 16(2), 95-102.

Schwartz, S. H. (1994). Beyond individualism/collectivism: new cultural dimensions of value. In Kim, U., Triandis, H.C., Kagitcibasi, C., Choi, S.C. and Yoon, G. (Eds), Individualism and collectivism: Theory, method and applications. Thousand Oaks, CA: Sage, 85-119.

Segal-Horn, S., \& Davison, H. (1992). Global markets, the global consumer and international retailing. Journal of Global Marketing, 5(3), 31-61.

Sethi, S. P. (1971). Comparative cluster analysis for world markets. Journal of Marketing Research, 8(3), 348-354.

Shiu, E. C-C., \& Dawson, J. A. (2002). Cross-national consumer segmentation of Internet shopping for Britain and Taiwan. The Service Industries Journal, 22(1), 147-166.

Sin, L. Y. M., Cheung, G. W. H., \& Lee, R. (1999). Methodology in cross-cultural consumer research: A review and critical assessment. Journal of International Consumer Marketing, 11(4), 75-96.

Smith, W. R. (1956). Product differentiation and market segmentation as alternative marketing strategies. Journal of Marketing, 21(1), 3-8.

Souiden, N. (2002). Segmenting the Arab markets on the basis of marketing stimuli. International Marketing Review, 19(6), 611-636.

Spreng, R. A., \& Chiou, J-S. (2002). A cross-cultural assessment of the satisfaction formation process. European Journal of Marketing, 36(7/8), 829-841. 
Steenkamp, J-B. E. M. (2001). The role of national culture in international marketing research. International Marketing Review, 18(1), 30-44.

Steenkamp, J-B. E. M., \& Baumgartner, H. (1998). Assessing measurement invariance in cross-national consumer research. Journal of Consumer Research, 25(1), 78-90.

Steenkamp, J-B. E. M., \& Ter Hofstede, F. (2002). International market segmentation: Issues and perspectives. International Journal of Research in Marketing, 19, (3), 185-213.

Ter Hofstede, F., Steenkamp, J.-B.E.M., \& Wedel, M. (1999). International market segmentation based on consumer-product relations. Journal of Marketing Research, 36(1), 1-17.

Terasaki, S. (2016). Cosmopolitan consumers: Research overview and research opportunities. Journal of International Business Research, 15(1), 32-45.

Vandermerwe, S., \& L'Huillier, M-A. (1989). Euro-consumers in 1992. Business Horizons, 32(1), 34-40.

Verhage, B. J., Dahringer, L. D., \& Cundiff, E. W. (1989). Will a global marketing strategy work? An energy conservation perspective. Journal of the Academy of Marketing Science, 17(2), 129-136.

Walters, P. G. (1997). Global market segmentation: methodologies and challenges. Journal of Marketing Management, 13(1-3), 165-177.

Wedel, M., \& Kamakura, W. A. (1998). Market segmentation - Conceptual and methodological foundations. Boston, MA: Kluwer Academic Publishers.

Wedel, M., Ter Hofstede, F., \& Steenkamp, J-B. E. M. (1998). Mixture model analysis of complex samples. Journal of Classification, 15(2), 225-244.

Wind, Y. (1978). Issues and advances in segmentation research. Journal of Marketing Research, 15(3), 317-337.

Wind, Y., \& Douglas, S. P. (1972). International market segmentation. European Journal of Marketing, $6(1), 12-25$.

Wu, S. (2001). Benefit segmentation: An empirical study for on-line marketing. Asia Pacific Journal of Marketing and Logistics, 13(4), 3-18.

Yavas, U., Verhage, B. J., \& Green, R. T. (1992). Global consumer segmentation versus local market orientation: Empirical findings. Management International Review, 32(3), 265-272.

Yilmazsoy, B., \& Schmidbauer, H. (2015). Green segmentation: A cross-national study. Marketing Intelligence \& Planning, 33(7), 981-1003.

Young, S., Ott, L., \& Feigin, B. (1978). Some practical considerations in market segmentation. Journal of Marketing Research, 15(3), 405-412. 